\title{
EchoGéo
}

$10 \mid 2009$

La piraterie

\section{Atlas de l'Inde. Une fulgurante ascension}

Compte rendu

\section{OpenEdition}

Journals

\section{Édition électronique}

URL : https://journals.openedition.org/echogeo/11435

DOI : $10.4000 /$ echogeo. 11435

ISSN : 1963-1197

\section{Éditeur}

Pôle de recherche pour l'organisation et la diffusion de l'information géographique (CNRS UMR 8586)

\section{Référence électronique}

"Atlas de l'Inde. Une fulgurante ascension », EchoGéo [En ligne], 10 | 2009, mis en ligne le 13 octobre 2009, consulté le 16 septembre 2021. URL : http://journals.openedition.org/echogeo/11435; DOI : https://doi.org/10.4000/echogeo.11435

Ce document a été généré automatiquement le 16 septembre 2021.

EchoGéo est mis à disposition selon les termes de la licence Creative Commons Attribution - Pas d'Utilisation Commerciale - Pas de Modification 4.0 International (CC BY-NC-ND) 


\title{
Atlas de l'Inde. Une fulgurante ascension
}

\author{
Compte rendu
}

1 La vertu de cet atlas dirigé par Philippe Cadène et très complet dirigé par Philippe Cadène, professeur à l'Université Paris 7 , est de saisir le sous-continent indien dans sa complexité, au travers d'une vision synoptique qui permet de comprendre les enjeux auxquels les autorités et la population indienne doivent faire face. À travers plus d'une centaine de cartes conçues et réalisées à partir de données très originales pour certaines accompagnées de textes riches et précis, il incite à dépasser un certain nombre de clichés. Le sous-titre - «Une fulgurante ascension" - indique d'emblée le parti pris retenu: présenter l'Union indienne sous un angle résolument contemporain, au travers de données rarement

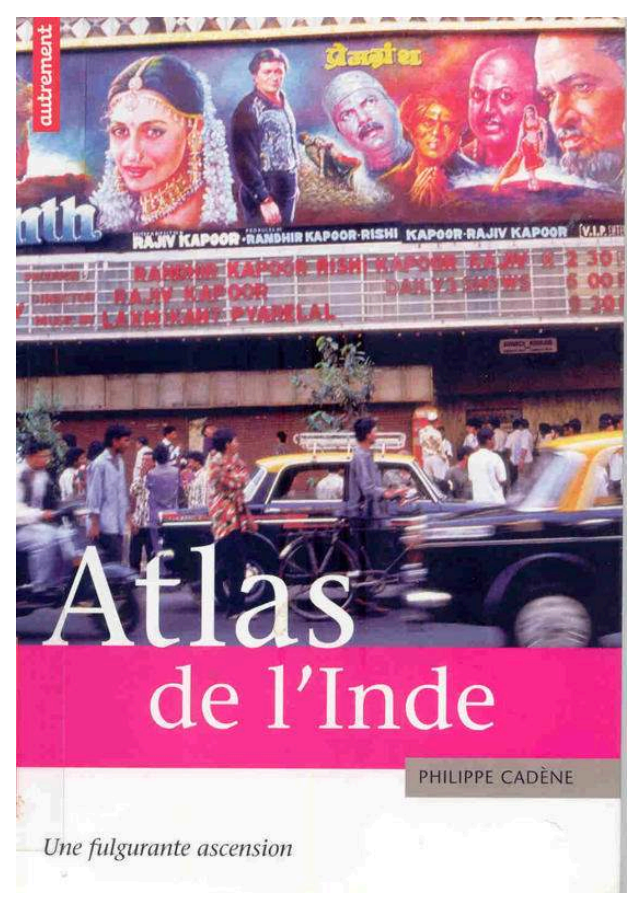
antérieures à l'an 2000, et partie prenante de la mondialisation. Il met en avant notamment les dynamiques urbaines (partie 2), la mise en compétition des activités (partie 4), la montée en puissance de l'Inde à l'échelle internationale (partie 5), tout en n'omettant pas les espaces ruraux, dans une partie toutefois plus brève (3).

2 Les facteurs de construction de la société indienne (les castes, la complexité linguistique et religieuse) et de l'État moderne (élaboration du système fédéral, équilibres politiques et participation à la vie publique via les élections) sont abordés dans une première partie. 
3 La seconde partie présente les dynamiques démographiques ainsi que l'organisation territoriale, mettant en avant le réseau urbain, notamment les principales métropoles qui font l'objet chacune d'une double page. Une tentative de cartographier le rayonnement économique des grandes villes à l'échelle du pays fait notamment l'objet de planches originales très intéressantes (p.30-37), qui justifient le fait a priori surprenant d'avoir ravalé Chennai au rang de métropole secondaire. Pour autant, un jeu de cartes fort utile, à l'échelle plus fine des 593 districts, incite à réfléchir sur la pauvreté et l'Inde des marges (p. 26-27).

4 La troisième partie présente l'agriculture et l'évolution des espaces ruraux après les trois révolutions verte, jaune et blanche. Si deux cartes détaillent les activités halieutiques (p.49), aucune pourtant ne mentionne les activités aquacoles pourtant vectrices d'un dynamisme certain.

5 Succède une partie consacrée aux activités économiques et au développement urbain. L'analyse dans cette partie insiste sur les effets des réformes libérales des années post-1991 dans l'organisation du territoire, notamment en termes d'infrastructures.. Le propos se veut nuancé sur la situation du pays : ainsi la double page sur « les services financiers » fait voisiner une carte des sièges sociaux des grandes banques indiennes avec un long texte et une carte consacrés au microcrédit.

6 La dernière partie est résolument géopolitique, consacrée à la place de l'Inde dans le monde, utilisant la projection de Peters pour les planisphères. Elle comprend des cartes illustrant les échanges commerciaux, les investissements indiens à l'étranger, la diaspora, mais aussi les stratégies d'alliance en Asie du Sud et l'environnement géostratégique, Elle se conclut par une double page qui revient sur la dimension culturelle (cinéma, gastronomie) de l'affirmation de cette partie du monde.

7 Contrainte inhérente au format de cette collection, la dimension de certains documents, à l'instar de la chronologie de la page 13, rend la lecture parfois délicate. Il en va de même pour les choix opérés s'agissant de l'échelle et du maillage territorial retenus pour les cartes : on peut regretter que celles présentant des données à l'échelle des 593 districts soient souvent de petit format, les grands formats privilégiant des cartes plus simples à l'échelle des 35 Etats. Par ailleurs, si dès la première page, Philippe Cadène prévient le lecteur que les frontières adoptées pour cet atlas sont les frontières de l'Union Indienne, la cartographie sur l'Inde en France de la page 77 renvoie en fait à l'ensemble sud-asiatique. Enfin, mais c'est encore une limite liée à l'exercice de vulgarisation, qui est fort bien mené, le spécialiste regrettera qu'il y ait seulement en fin d'ouvrage une bibliographie générale sur l'Inde, qui ne permet pas de faire état de l'ensemble des sources utilisées.

[Philippe Cadène ; Guillaume Balavoine, Paris, Autrement, 2008, 80 p.]

par Anthony Goreau-Ponceaud et Aurélie Varrel 